\title{
The 5-HT 6 Receptor Antagonist SB-27 1046 Reverses Scopolamine-Disrupted Consolidation of a Passive Avoidance Task and Ameliorates Spatial Task Deficits in Aged Rats
}

\author{
Andrew G Foley', Keith J Murphy', Warren D Hirst'ㄹ, Helen C Gallagher', Jim J Hagan ${ }^{3}$, Neil Upton $^{2}$, Frank S \\ Walsh ${ }^{2}$ and Ciaran M Regan*,' \\ 'Department of Pharmacology, Conway Institute, University College Dublin, Belfield, Ireland; 'Neurology \& Gl, GlaxoSmithKline, Harlow, UK; \\ ${ }^{3}$ Psychiatry Centres of Excellence for Drug Discovery, GlaxoSmithKline, Harlow, UK
}

\begin{abstract}
The highly potent and selective 5-HT6 receptor antagonist SB-27I046 [5-chloro-N-(4-methoxy-3-piperazin- I-yl-phenyl)-3-methyl-2benzothiophenesulfonamide] has previously been demonstrated to improve retention significantly in a spatial water maze paradigm in adult rats. However, SB-27 1046 did not have any effect on task acquisition. As these apparently contradictory findings may be reconciled by a prime influence of SB-27I046 on memory consolidation, the ability of this compound to reverse the discrete temporal action of a cholinergic antagonist in the 6-h period following passive avoidance training was investigated. SB-27I046, given orally, by gavage, 30 min prior to training Wistar rats in a step-through, light-dark passive avoidance task, was found to reverse significantly the amnesia produced by administering scopolamine $(0.8 \mathrm{mg} / \mathrm{kg}$, intraperitoneal $)$ in the 6 -h post-training period. The effect was dose-dependent over a range of $3-20 \mathrm{mg} / \mathrm{kg}$. Further, we investigated the cognition-enhancing effects of chronic SB-27l 046 administration ( 0 or 20 mg/ $/ \mathrm{kg} / \mathrm{day} ; 40$ days) on the acquisition and consolidation of a water maze spatial learning task in a population of 20-month-old Wistar rats with age-related learning deficits. Drug treatment progressively and significantly decreased platform swim angle and escape latencies over the five sequential trials on four consecutive daily sessions compared to vehicle-treated controls. SB-27I046 also improved task recall as measured by significant increases in the searching of the target quadrant on post-training days $\mid$ and 3 , when the animals would have been substantially drug-free. This significant improvement of task recall suggests SB-271046, in addition to inducing symptomatic cognition-enhancing actions, also attenuates age-related decline in neural function.

Neuropsychopharmacology (2004) 29, 93-100, advance online publication, 22 October 2003; doi: I 0.1038/sj.npp. I 300332
\end{abstract}

Keywords: acute and chronic administration; search strategy; swim angle; probe trial; cholinergic deficits; neuroplasticity

\section{INTRODUCTION}

Serotonin receptors of the $5-\mathrm{HT}_{6}$ subclass belong to the family of $G$ protein-coupled receptors that positively influence adenylate cyclase (Monsma et al, 1993; Ruat et al, 1993). These receptors are mainly found in the central nervous system and ultrastructural studies suggest that they mediate a postsynaptic, rather than autoreceptor, role (Gérard et al, 1997; Hamon et al, 1999).

Recently, selective antagonists of the $5-\mathrm{HT}_{6}$ receptor have become available. The first reported $5-\mathrm{HT}_{6}$ receptor antagonists were Ro-04-6790 [4-amino- $N$-(2,6 bis-methyla-

\footnotetext{
*Correspondence: Ciaran M Regan, Department Pharmacology, Conway Institute, University College Dublin, Belfield, Dublin 4, Ireland, Tel: + 353 | 7161510, Fax: + 353 | 2692749,

E-mail: Ciaran.Regan@ucd.ie

Received 20 June 2003; revised 09 September 2003; accepted 09 December 2003

Online publication: 17 September 2003 at http://www.acnp.org/ citations/Npp09| 70303272/default.pdf
}

mino-pyrimidin-4-yl)-benzene sulfonamide] and Ro-630563 [4-amino- $N$-(2,6 bis-methylamino-pyridin-4-yl)-benzene sulfonamide] (Sleight $e t$ al, 1998). These were followed by the potent and highly selective $5-\mathrm{HT}_{6}$ antagonists $\mathrm{SB}-$ 271046 [5-chloro- $N$-(4-methoxy-3-piperazin-1-yl-phenyl)3-methyl-2-benzothiophenesulfonamide], SB-357134 [N(2,5-Dibromo-3-fluorophenyl)-4-methoxy-3-piperazin-1-ylbenzenesulfonamide] (Bromidge et al, 1999, 2001; Routledge et al, 2000; Stean et al, 2002), and the radioligand ${ }^{[25}$ I]SB-258585 [5-iodo- $N$-[4-methoxy-3-(4-methylpiperazin-1-yl-phenyl]benzenesulfonamide] (Hirst et al, 2000).

Early studies with Ro-04-6790 demonstrated an increase in the stretching behavior (Bentley et al, 1999) and reversal of scopolamine-induced rotation in 6-OHDA-lesioned rats (Bourson et al, 1998). These observations suggested that 5$\mathrm{HT}_{6}$ receptors mediate a tonic inhibition of cholinergic neurons and that $5-\mathrm{HT}_{6}$ receptor antagonists may play a role in the treatment of learning and memory disorders (Reavill and Rogers, 2001). However, microdialysis studies have shown that SB-271046 modulates excitatory amino- 
acid neurotransmission (Dawson et al, 2000, 2001), which may also contribute to this receptor's role in cognition.

$5-\mathrm{HT}_{6}$ receptor antagonism alone appears to have positive effects on cognitive processes in rodents. In the Morris water maze task, $5-\mathrm{HT}_{6}$ receptor antagonism with Ro-046790, SB-357134, and SB-271046 significantly improved task retention, but had little effect on task acquisition (Rogers and Hagan, 2001; Woolley et al, 2001). Furthermore, 5- $\mathrm{HT}_{6}$ receptor antagonists have been demonstrated to reverse learning deficits induced by cholinergic antagonists. For example, $5-\mathrm{HT}_{6}$ receptor antagonist Ro-04-6790 reverses scopolamine-induced deficits in avoidance conditioning and autoshaping tasks (Meneses, 2001; Bös et al, 2001). These data suggest the cognition-enhancing properties of 5$\mathrm{HT}_{6}$ receptor antagonists to be predominantly exerted in the post-training period of memory consolidation.

The cognitive deficits associated with normal aging correlate strongly with a significant decline in the cholinergic neurotransmission system, particularly in Alzheimer's patients (Coyle et al, 1983; Perry et al, 1992; Whitehouse et al, 1982). Since SB-271046 had been demonstrated to improve recall, but not acquisition, of a spatial learning task in normal animals and to prevent scopolamine-induced amnesia in mature animals, the current study investigated its influence on the cholinergic mechanisms of memory consolidation and age-related memory deficits. The ability of SB-271046 to reverse scopolamine disruption of a discrete temporal involvement of a cholinergic mechanism in the post-training period of avoidance conditioning (Doyle and Regan, 1993) was employed to investigate its influence on memory consolidation. Secondly, a water maze spatial learning paradigm, in which age-related cognitive deficits in rodents have been best characterized (Gage et al, 1984; Rapp et al, 1987; Gallagher and Pelleymounter, 1988; van der Staay and de Jonge, 1993), was employed to determine the cognition-enhancing potency of SB-271046 in aged animals.

\section{EXPERIMENTAL PROCEDURES}

\section{Animal Maintenance}

Experimentally naïve male Wistar rats were employed in all studies. The animals were purpose bred at the Biomedical Facility, University College Dublin, and maintained in standard laboratory conditions until the time of experimental use at either 80 days or 20 months old. Animals were introduced to the experimental holding rooms at least 3 days prior to the commencement of any study, housed individually during this period, and maintained at $22-24^{\circ} \mathrm{C}$ on a standard $12 \mathrm{~h}$ light/dark cycle, with food and water available ad libitum. All experimental procedures were approved by the Animal Research Ethics Committee of University College, Dublin, and were carried out by individuals who held the appropriate license issued by the Department of Health.

\section{Drug Administration}

SB-271046 was administered orally, by gavage, in $1 \%$ methylcellulose solution. All animals were examined and weighed daily. For acute studies, postnatal day 80 animals were administered a single dose of SB-271046 at 1, 3, 10, or $20 \mathrm{mg} / \mathrm{kg} 30 \mathrm{~min}$ prior to training in the passive avoidance paradigm $(n=6$ or 7$)$. In the chronic studies, animals were treated once daily for 40 days with SB-271046 at a concentration of 10 or $20 \mathrm{mg} / \mathrm{kg} \quad(n=6$ or 7$)$. Drug treatment ceased $24 \mathrm{~h}$ prior to the first training session in the water maze paradigm. In all cases, the drug was administered by gavage and vehicle-treated controls were employed for comparison.

\section{Passive Avoidance Conditioning}

Behavioral assessment. In this protocol, postnatal day 80 animals were introduced to the training environment 5 days prior to training, and individually housed according to standard conditions. Animals were left to habituate to the environment for days 1-3 with no handling; on days 4 and 5 animals were handled, their weight monitored and spontaneous behavior was assessed in an open-field apparatus for $5 \mathrm{~min}$. The open-field apparatus consisted of black-painted wood $620 \mathrm{~mm}^{2}$ with walls $150 \mathrm{~mm}$ high. The white-painted floor of the apparatus was ruled from side to side, dividing it into a series of boxes $77 \times 77 \mathrm{~mm}^{2}$. Locomotor activity was measured as the number of lines crossed in $300 \mathrm{~s}$. Other behaviors assessed were rearing, grooming, piloerection, defecation, and posture. These behavioral assessments were carried out to monitor the possible unexpected drug effects confounding their behavior.

Apparatus. Animals were trained in a single-trial, stepthrough, light-dark passive avoidance paradigm. The training apparatus consisted of a chamber $300 \mathrm{~mm}$ in length, $260 \mathrm{~mm}$ wide, and $270 \mathrm{~mm}$ in height, constructed to established designs. The front and top were transparent, allowing the experimenter to observe the behavior of the animal inside the apparatus. The chamber was divided into two compartments, separated by a central shutter that contained a small opening $50 \mathrm{~mm}$ wide and $75 \mathrm{~mm}$ high set close to the front of the chamber. The smaller of the compartments measured $9 \mathrm{~mm}$ in width and contained a low-power $(6 \mathrm{~V})$ illumination source. The larger compartment measured $210 \mathrm{~mm}$ in width and was not illuminated. The floor of this dark compartment consisted of a grid of 16 horizontal stainless-steel bars that were $5 \mathrm{~mm}$ in diameter and spaced $12.5 \mathrm{~mm}$ apart. A current generator supplied $0.75 \mathrm{~mA}$ to the grid floor, which was scrambled once every $0.5 \mathrm{~s}$ across the 16 bars. A resistance range of $40-60 \mathrm{~m} \Omega$ was calculated for a control group of rats $(250-350 \mathrm{~g})$, and the apparatus was calibrated accordingly. An electronic circuit detecting the resistance of the animal ensured an accurate current delivery by automatic variation of the voltage with change in resistance.

Training protocol. This was carried out as described previously (Fox et al, 1995). On the day of training, animals were placed facing the rear of the light compartment of the apparatus, immediately after spontaneous behavior was assessed. The timer was started once the animal has completely turned to face the front of the chamber. Latency to enter the dark chamber was recorded (usually $<20 \mathrm{~s}$ ), and having completely entered the dark compartment foot 
shock was administered to the animal, which immediately returned to the light compartment. Animals were then returned to their home cages. Between each training session, both compartments of the chamber were cleaned to remove any confounding olfactory cues. Recall of this inhibitory stimulus was evaluated $24 \mathrm{~h}$ post-training by returning the animal into the light chamber and recording their latency to enter the dark chamber, a criterion time of $600 \mathrm{~s}$ was employed. Animals were rendered amnesic by the intraperitoneal (i.p.) administration of scopolamine $(0.8 \mathrm{mg} / \mathrm{kg}$, i.p. $)$ at the $6 \mathrm{~h}$ post-training time point. The ability of SB-271046 to reverse this scopolamine-induced amnesia was determined by its acute administration at doses of $1,3,10$, or $20 \mathrm{mg} / \mathrm{kg}$ given $30 \mathrm{~min}$ prior to passive avoidance training.

\section{Water Maze Spatial Learning Paradigm}

Behavioral assessment. Aged animals (20 months), previously administered SB-271046 for a period of 40 days, were introduced to the training environment and assessed for spontaneous behavior as described above.

Apparatus. The water maze apparatus consisted of a circular pool $(1 \mathrm{~m}$ diameter, $80 \mathrm{~cm}$ high) constructed in black Perspex from established designs. The temperature was maintained at $26^{\circ} \mathrm{C}$ by a heating element, which was covered by a false bottom, and a pump was used to circulate the water. A platform $(11 \mathrm{~cm}$ diameter $)$ constructed from black Perspex was submerged $1.5 \mathrm{~cm}$ below the water surface. During training, the platform was hidden in one quadrant of the maze $30 \mathrm{~cm}$ from the sidewall. The black Perspex used in the construction of the maze and platform offered no intramaze cues to guide escape behavior. By contrast, the training room offered several strong extramaze visual cues to aid the formation of the spatial map necessary for escape learning. An automated tracking system, 'Water maze 3.1', was employed. This program analyzes video images acquired via a digital camera and an image acquisition board that determined path length, swim speed, angle of direction (defined as the angle between the initial direction of swim and the endpoint platform), and the number of entries and duration of swim time spent in each quadrant of the water maze.

Training. The standard protocol employed to evaluate spatial learning ability in aged animals has been described previously (Murphy et al, 1996). Each trial started with the rat placed facing the wall of the maze at one of three designated locations. The rat was allowed to explore the maze and the time taken to find the hidden platform, within a $60 \mathrm{~s}$ criterion period, was defined as the escape latency time. On the first trial, rats failing to locate the platform within the $60 \mathrm{~s}$ period were placed on it for $10 \mathrm{~s}$. In subsequent trials, animals failing to locate the platform were not shown it again. Escape latencies were measured over five trials with an intertrial rest interval of $300 \mathrm{~s}$. Animals were trained in daily sessions over 4 days. Recall of platform position was assessed by a probe test, at 1 and 3 days following the final training session, in which the platform was removed and animals were allowed to explore the maze for $60 \mathrm{~s}$. The time spent in each quadrant was recorded and used to compare recall of the platform position by each treatment group.

\section{Data Analysis}

Data from the passive avoidance studies were analyzed by ANOVA followed by the Bonferroni post hoc test. Water maze behavioral parameters were monitored using Watermaze 3.1, a Labview $\AA$ executable image motion analyzer written by Matthias Grossmann (Dresden, Germany). This was linked to a CCD camera via an image acquisition card (IMAQ-1408, National Instruments Co., UK). All data were calculated and graphed as mean \pm SEM for all trials of all sessions and the presence of significant difference between treatments was determined by repeat measures ANOVA and post hoc Bonferroni or Mann-Whitney $U$-test analysis of this data set. In all cases, values of $p<0.05$ were deemed to be significant.

\section{RESULTS}

\section{Acute Administration of SB-271046 Reverses Scopolamine-Induced Amnesia of a Passive Avoidance Paradigm in Mature Rats}

In comparison to vehicle-treated control animals, scopolamine was effective at rendering animals amnesic, as its administration at the $6 \mathrm{~h}$ post-training time point significantly reduced the recall latency tested at $24 \mathrm{~h}$ post-training $(p<0.01$, Bonferroni post hoc analysis). SB-271046 reversed this scopolamine-induced amnesia in a dose-dependent manner, with significant effects observed after administration of 3,10 , and $20 \mathrm{mg} / \mathrm{kg}$. Analysis of $24 \mathrm{~h}$ recall latencies revealed a protective effect against scopolamine-induced amnesia following pretraining administration of SB-271046 (Figure 1; F[3,25] $=3.37, p=0.037$ ).

\section{Aged Rats Exhibit Spatial Learning Deficits in the Water Maze Paradigm}

Across the 20 training trials in the water maze, both mature and aged animals progressively decreased their escape latencies over the sequential trials and sessions $(\mathrm{F}[19,240]=2.52 ; p=0.0007)$. Analysis of spatial learning behavior in the water maze showed significant differences between mature animals treated chronically with methylcellulose vehicle and similarly treated aged counterparts. As judged by their latency time to reach the platform, aged animals displayed a clear deficit in the acquisition of platform location compared with mature animals (Figure 2a and Table 1). The age-related acquisition deficit was found to be highly significant across all sessions (two-way ANOVA; $\mathrm{F}[1,240]=21.48 ; p<0.0001$ ), with post hoc analysis revealing specific divergence on the first, third, and fourth days of training $(p<0.05)$.

Analysis of a second behavioral measure, angle of swim, offered further evidence of this age-dependent spatial learning deficit. The angle of swim parameter measures the initial heading of the animal from the starting position in relation to a direct line to the platform location. As such, this parameter is a measure of the accuracy of the search 


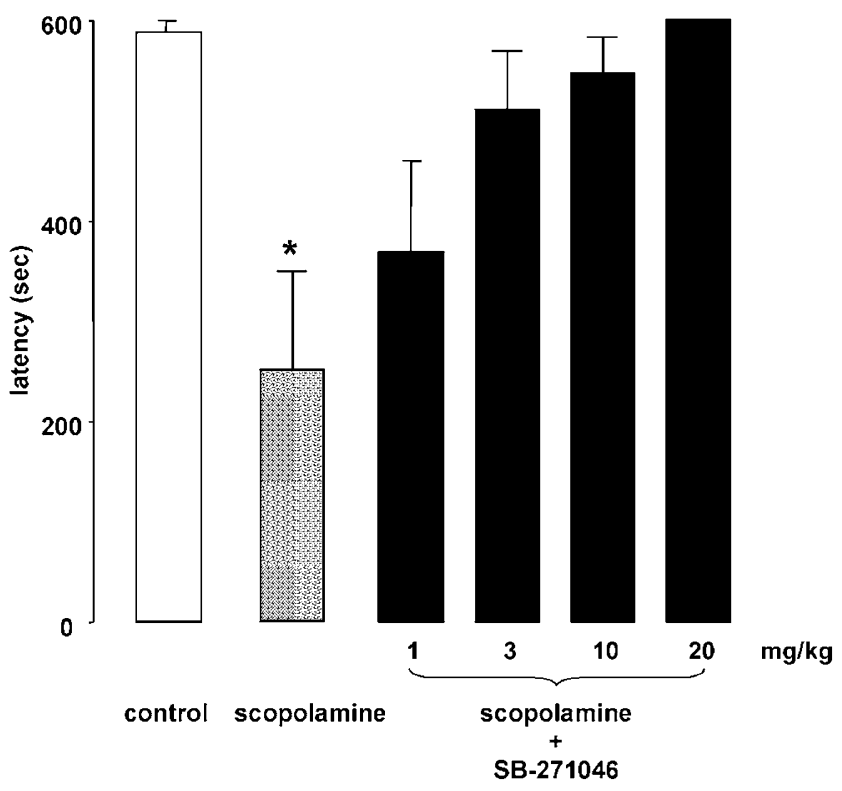

Figure I Influence of SB-27I046 on scopolamine-induced amnesia of a passive avoidance response. Data represent the mean \pm SEM avoidance latency at the $24 \mathrm{~h}$ recall time. A significant difference from control animals is indicated with an asterisk (Bonferroni post hoc analysis, $p<0.05$ ).

strategy employed by the animal in solving the task. Initial acquisition, as judged by performance on the final trial of the first session, suggested mature and aged animals to be equivalent in their performance (Figure 2b). However, the swim angle of mature animals reduced significantly over the training sessions, while that of the aged animals did not show marked improvement in the search strategy employed (Figure $2 \mathrm{~b}$ and $\mathrm{c} ; \mathrm{F}[1,47]=6.25, p=0.016$ ). This difference in water maze learning became significant at the end of the fourth training session $(p<0.05$, Bonferroni post hoc analysis). These data reveal marked deficits in the learning ability of aged animals.

\section{Chronic Administration of SB-271046 Enhances Spatial Learning in Aged Animals}

Chronic treatment of aged animals with SB-271046 significantly reduced escape latencies in the water maze task (Figure 3a and Table 1). At a dose of $20 \mathrm{mg} / \mathrm{kg} \mathrm{SB}-271046$, the time required to locate the platform was significantly reduced by the final trial of the first session, as compared to the methylcellulose controls (Figure 3a). Task acquisition was also improved at a dose of $10 \mathrm{mg} / \mathrm{kg}$ from session 2 onwards. Analysis of escape latency over the course of training demonstrated significantly improved performance at both drug concentrations employed $(\mathrm{F}[2,200]=38.68$, $p<0.0001)$. Moreover, at the higher dose employed $(20 \mathrm{mg} /$ $\mathrm{kg}$ ), analysis of performance by two-way ANOVA indicated chronic SB-271046 treatment not only to reverse age-related deficits in spatial learning ability of aged animals but also to enhance performance significantly over that observed in mature, methylcellulose-treated animals $(\mathrm{F}[1,240]=8.11$; $p=0.0048)$.

The improved spatial learning observed in aged rats treated chronically with SB-271046 could not be attributed
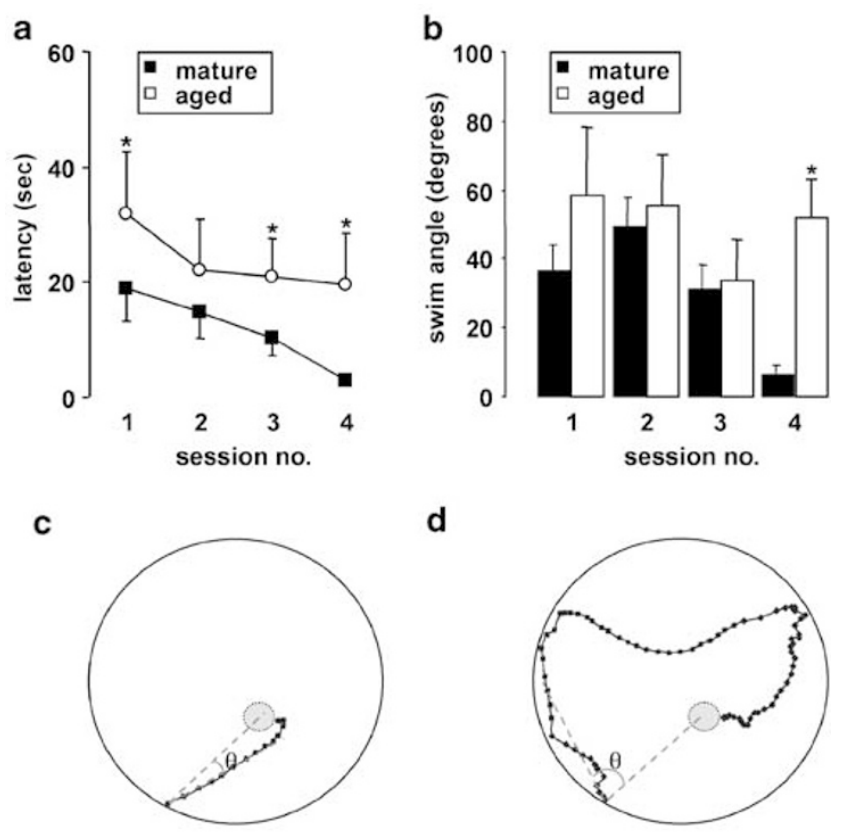

d

mature animal - session 4

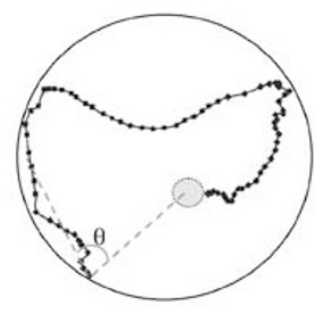

aged animal - session 4

Figure 2 Acquisition of the water maze task over four daily sessions in mature (postnatal day 80 ) and aged (20 month) animals. (a) Escape latency mean \pm SEM on the fifth and final trial of each of the four training sessions are shown. Repeat measures two-way ANOVA reveals improved performance with each successive session $(F[19,240]=2.52 ; p=0.0007)$, but a marked deficit in the aged animals over the four sessions $(\mathrm{F}[\mathrm{I}, 240]=21.48 ; \quad p<0.000 \mathrm{I})$. Bonferroni post hoc analysis indicates significant difference in the final trial of sessions I, 3, and $4\left({ }^{*} p<0.05\right)$. The mean \pm SEM of swim angle (degrees) on the fifth and final trial of each of the four training sessions is shown in (b). Two-way ANOVA demonstrates a significant deficit in aged animals $(F[1,47]=6.25$, $p=0.016)$ and individual values significantly different from the mature animal group are indicated with an asterisk (Bonferroni post hoc analysis; $p<0.05)$. Representative swim paths for mature and aged animals are shown in (c); in each case the angle of swim $(\theta)$ is that measured between the axes of start-to-platform and start-to-animal positions after a $25 \mathrm{~cm}$ swim as indicated by the dotted lines.

to altered locomotor activity in the pretraining period (Table 2). Moreover, it was not attributable to improved motor ability, as swim speed was equivalent in drug-treated animals as compared to methylcellulose-treated controls (Table 3). Rather, quantitative analysis of search strategy revealed that chronic SB-271046 treatment decreased swim angle, as compared to that observed in age-matched, methylcellulose controls (Figure 3b). Specifically, at the highest dose employed $(20 \mathrm{mg} / \mathrm{kg})$, there was a significant reduction in departure angle from the start position to the hidden platform $(\mathrm{F}[1,43]=20.43 ; p<0.0001)$.

\section{Chronic Administration of SB-271046 Improves Recall of a Spatial Learning Task in Aged Animals}

The influence of SB-271046 on the recall of the spatial learning task was determined using a probe test, in which the escape platform was removed from the water maze, on days 1 and 3 following the final training session. Animals that had been previously treated by chronic administration with SB-271046 spent significantly more time searching in 
Table I Influence of Age and Chronic SB-271046 Treatment on Animal Escape Latency in the Water Maze Task

\begin{tabular}{|c|c|c|c|c|}
\hline Trial no. & Mature & Aged & Aged+SB-27 I 046 (10 mg/kg) & Aged+SB-27 $1046(20 \mathrm{mg} / \mathrm{kg})$ \\
\hline I & $41.87 \pm 6.1$ & $50.36 \pm 6.1$ & $50.23 \pm 5.7$ & $49.37 \pm 6.8$ \\
\hline 2 & $23.46 \pm 4.9$ & $48.78 \pm 9.2$ & $43.53 \pm 6.9$ & $29.56 \pm 12.5$ \\
\hline 3 & $22.86 \pm 6.8$ & $39.97 \pm 8.5$ & $31.65 \pm 10.7$ & $34.85 \pm 9.5$ \\
\hline 4 & $31.06 \pm 7.5$ & $38.49 \pm 10.5$ & $44.48 \pm 8.7$ & $19.39 \pm 8.7$ \\
\hline 5 & $18.93 \pm 5.7 *$ & $31.89 \pm 10.7$ & $22.80 \pm 10.4$ & $2.94 \pm 1.4 *$ \\
\hline 6 & $27.08 \pm 6.2$ & $32.15 \pm 9.0$ & $27.87 \pm 7.4$ & $10.29 \pm 2.7 *$ \\
\hline 7 & $22.64 \pm 7.2$ & $31.42 \pm 6.8$ & $36.62 \pm 9.5$ & $26.29 \pm 10.9$ \\
\hline 8 & $22.31 \pm 8.6$ & $30.41 \pm 9.9$ & $37.77 \pm 9.4$ & $26.75 \pm 7.8$ \\
\hline 9 & $32.89 \pm 6.9$ & $31.21 \pm 9.6$ & $24.39 \pm 9.1$ & $23.40 \pm 9.8$ \\
\hline 10 & $|4.8| \pm 4.4$ & $22.19 \pm 8.9$ & $4.75 \pm 1.4$ & $8.01 \pm 3.1$ \\
\hline II & $28.28 \pm 7.7$ & $26.06 \pm 9.3$ & $12.30 \pm 2.8$ & $14.93 \pm 4.9$ \\
\hline 12 & $20.29 \pm 6.7$ & $15.14 \pm 7.8$ & $18.34 \pm 9.2$ & $5.67 \pm 2.4$ \\
\hline 13 & $23.28 \pm 7.2$ & $26.36 \pm 8.9$ & $4.85 \pm 1.3$ & $8.98 \pm 3.9$ \\
\hline 14 & $30.42 \pm 4.7$ & $31.93 \pm 9.7$ & $15.48 \pm 6.0$ & $7.80 \pm 3.6 *$ \\
\hline 15 & $10.37 \pm 3.0 *$ & $21.07 \pm 6.6$ & $3.21 \pm 1.31 *$ & $5.83 \pm 1.54 *$ \\
\hline 16 & $9.26 \pm 1.1 *$ & $41.75 \pm 9.5$ & $24.67 \pm 10.4$ & $4.61 \pm 1.2 *$ \\
\hline 17 & $6.98 \pm 3.5$ & $25.03 \pm 8.5$ & $12.50 \pm 6.9$ & $11.75 \pm 5.1$ \\
\hline 18 & $16.42 \pm 6.5$ & $25.50 \pm 8.1$ & $19.96 \pm 8.6$ & $4.67 \pm 1.1$ \\
\hline 19 & $6.52 \pm 0.8$ & $31.80 \pm 9.5$ & $14.96 \pm 6.9$ & $7.65 \pm 2.2^{*}$ \\
\hline 20 & $2.92 \pm 0.9 *$ & $19.73 \pm 8.7$ & $6.93 \pm 2.6$ & $3.21 \pm 1.9 *$ \\
\hline
\end{tabular}

Data represent the mean \pm SEM escape latency measured as the time to locate the hidden platform of the water maze. Significant difference from aged is indicated by an asterisk (Bonferroni post hoc analysis, $p<0.05,6 \leqslant n \leqslant 7$ ).

the target quadrant as compared to control animals (Figure 4). Chronic doses of 10 or $20 \mathrm{mg} / \mathrm{kg} \mathrm{SB}-271046$ resulted in the animal groups spending a significantly greater period of the test time in the target quadrant on post-training day 1 (Figure 4a). This perseveration towards the former location of the escape platform in the target quadrant is evident in the representative swim traces illustrated in Figure $4 \mathrm{~b}$.

The improved recall resulting from chronic SB-271046 treatment was persisting, as the animal groups receiving either 10 or $20 \mathrm{mg} / \mathrm{kg}$ maintained their preference for the target quadrant on post-training day 3 (Figure 4c). By contrast, the control animals showed little preference for the target quadrant on either post-training days 1 or 3 . The improved recall for the target quadrant could not be attributed to enduring drug-induced change in swimming ability, as no change in the total swim distance was observed during the probe tests, and while an increase in swim speed was exhibited by the $20 \mathrm{mg} / \mathrm{kg}$ SB-271046 treatment group during the first probe trial, this is unlikely to effect the finding of increased preference for the target quadrant of the maze. If anything, this would have the opposite effect (Table 4).

\section{DISCUSSION}

The results of the present study demonstrate that an acute administration of a potent and selective $5-\mathrm{HT}_{6}$ receptor antagonist, SB-271046, was able to reverse scopolamine induced amnesia significantly in a step-through, light-dark passive avoidance task in mature rats. Given the cholinergic hypothesis of age-related memory decline (Bartus et al, 1982), the cognition-enhancing effects of this $5 \mathrm{HT}_{6}$ receptor antagonist on the acquisition and recall of a spatial learning task following chronic drug administration were investigated in a population of aged Wistar rats. In these studies, SB-271046 was observed to improve task acquisition, as evidenced by the significant reductions in escape latency and swim angle over five sequential trials on four consecutive training sessions. SB-271046 also improved task recall 1 and 3 days after training in this paradigm. The reduced swim speed observed during training at the highest drug dose employed is unlikely to relate to impaired motor performance, given that SB-271046 exhibited no locomotion deficits in open-field studies, but suggests a direct effect on improving search strategy.

In contrast to previous studies that have demonstrated the lack of effect of $5 \mathrm{HT}_{6}$ receptor antagonists on spatial task acquisition in mature animals (Rogers and Hagan, 2001; Woolley et al, 2001), the current findings indicate SB271046 to have a more profound cognition-enhancing action in aged animals, where effects on acquisition were demonstrated. These apparently contradictory findings may be reconciled by a prime influence of $5-\mathrm{HT}_{6}$ receptor antagonists on cholinergic process(es) of memory consolidation, a conclusion supported by the ability of SB-271046 to reverse the amnesic action of cholinergic antagonists, $6 \mathrm{~h}$ post-training. 


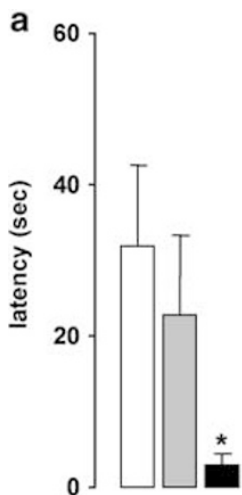

1

b

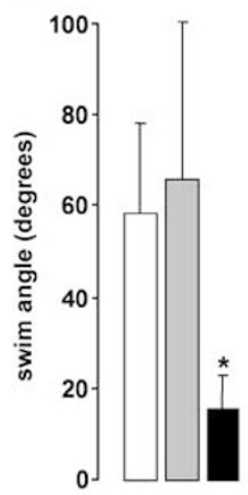

1

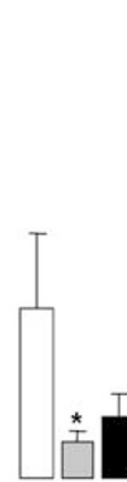

2

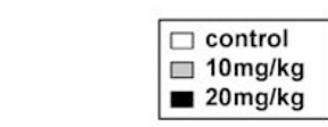

3

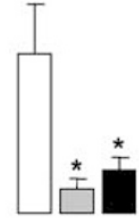

session no.

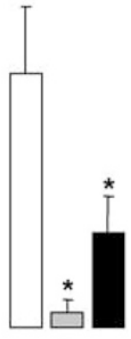

2

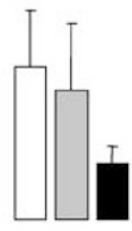

3

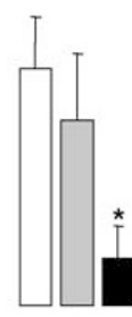

4

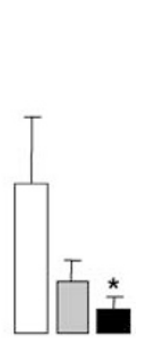

4 session no.

Figure 3 Influence of chronic SB-271046 administration on spatial learning in aged animals. (a) Mean \pm SEM escape latency in trial 5 of each training session are shown. Repeat measures analysis of variance indicates a significant drug-induced improvement in escape latency $(F[2,200]=38.68$; $p<0.000 \mathrm{I})$ in a dose-dependent manner $(\mathrm{F}[\mathrm{I}, \mathrm{I} 00]=54.9 ; p<0.000 \mathrm{I})$. The swim angle (degrees, mean \pm SEM) for each treatment group is shown in (b). Two-way ANOVA reveals a significant drug-dependent improvement in search strategy by aged animals $(F[2,58]=6.387 ; p=0.003)$, as compared to age-matched controls. Values significantly different from the control are indicated with an asterisk (Bonferroni post hoc analysis, $p<0.05)$

Table 2 Animal Behavior During Pretraining Open-Field Assessment

\begin{tabular}{|c|c|c|c|c|c|c|}
\hline & \multirow{2}{*}{\multicolumn{2}{|c|}{ Vehicle control }} & \multicolumn{4}{|c|}{ SB-27 I 046 (mg/kg) } \\
\hline & & & \multicolumn{2}{|c|}{10} & \multicolumn{2}{|c|}{20} \\
\hline & Day I & Day 2 & Day I & Day 2 & Day I & Day 2 \\
\hline Locomotion & $|5| \pm 8$ & $143 \pm 6$ & $158 \pm 14$ & $147 \pm 6$ & $162 \pm 12$ & $150 \pm 8$ \\
\hline Rearing & $32 \pm 3$ & $26 \pm 2$ & $35 \pm 3$ & $29 \pm 2$ & $33 \pm 4$ & $9 \pm 3$ \\
\hline
\end{tabular}

Table 3 Effect of Chronic SB-27I046 Treatment on Swim Speed of Aged Animals Performing the Water Maze Task

\begin{tabular}{lccc}
\hline & & \multicolumn{2}{c}{ SB-27 1 046 ( $\mathbf{m g} / \mathbf{k g})$} \\
\cline { 3 - 4 } Session number & Vehicle control & $\mathbf{1 0}$ & $\mathbf{2 0}$ \\
\hline 1 & $1.32 \pm 0.36$ & $0.81 \pm 0.26$ & $0.65 \pm 0.19$ \\
2 & $0.98 \pm 0.16$ & $0.77 \pm 0.31$ & $0.71 \pm 0.24$ \\
3 & $0.72 \pm 0.21$ & $0.61 \pm 0.14$ & $0.92 \pm 0.19$ \\
4 & $0.85 \pm 0.15$ & $1.19 \pm 0.32$ & $0.73 \pm 0.25$ \\
\hline
\end{tabular}

Data represent the mean \pm SEM animal swim speed $(\mathrm{m} / \mathrm{s})$ for trial 5 of each training session.

a

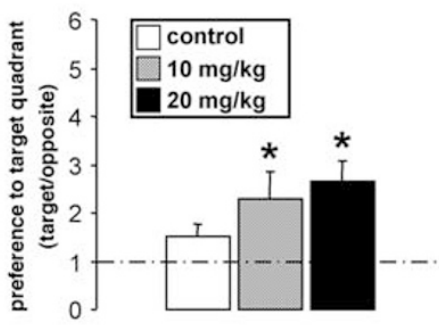

b

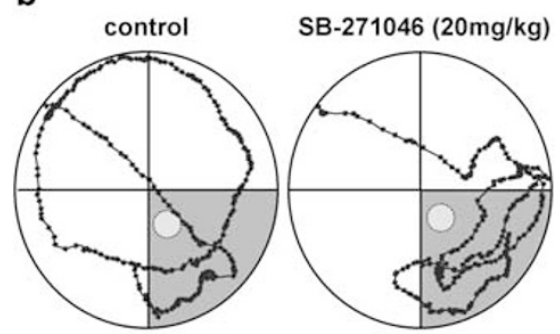

C

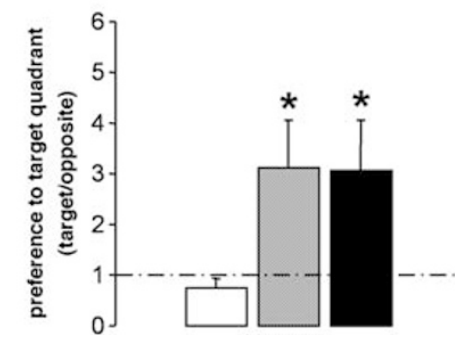

Figure 4 Influence of chronic SB-27I046 administration on recall of the water maze task in aged animals. The data shown in (a) represent the ratio of swimming time in target to time in the opposite quadrant at post-training day I; representative swim paths are illustrated in (b). The ratio of swimming time in target to time in the opposite quadrant at post-training day 3 is shown in (c). Chance performance (ratio value of $I$ ) is indicated by the dotted line. Values significantly different from the control are indicated by an asterisk (Mann-Whitney $U$-test, $p<0.05$ ).

The role of 5HT receptors in learning and memory formation remains equivocal, but a large body of evidence now indicates that presynaptic $5 \mathrm{HT}_{1 \mathrm{~A}}, 5 \mathrm{HT}_{1 \mathrm{~B}}, 5 \mathrm{HT}_{2 \mathrm{~A} / 2 \mathrm{C}}$, and $5 \mathrm{HT}_{3}$ receptors and postsynaptic $5 \mathrm{HT}_{2 \mathrm{~B} / 2 \mathrm{C}}$ and $5 \mathrm{HT}_{4}$ receptors are involved (Meneses, 1999). More recently, the 
Table 4 Effect of Chronic SB-27 1046 Treatment on Swim Distance and Speed of Aged Animals During Recall of a Water Maze Task

\begin{tabular}{|c|c|c|c|c|c|c|}
\hline \multirow[b]{3}{*}{ Recall day } & & & \multicolumn{4}{|c|}{ SB-27 I 046 (mg/kg) } \\
\hline & \multicolumn{2}{|c|}{ Vehicle control } & \multicolumn{2}{|c|}{10} & \multicolumn{2}{|c|}{20} \\
\hline & Distance $(\mathrm{cm})$ & Speed $(\mathrm{m} / \mathrm{s})$ & Distance $(\mathrm{cm})$ & Speed $(\mathrm{m} / \mathrm{s})$ & Distance $(\mathrm{cm})$ & Speed $(\mathrm{m} / \mathrm{s})$ \\
\hline । & $882.1 \pm 39.1$ & $1.54 \pm 0.22$ & $773.9 \pm 86.9$ & $1.11 \pm 0.24$ & $912.4 \pm 53.6$ & $2.32 \pm 0.22 *$ \\
\hline 3 & $783.5 \pm 35.3$ & $1.07 \pm 0.08$ & $742.7 \pm 76.7$ & $1.16 \pm 0.18$ & $861.1 \pm 38.6$ & $1.49 \pm 0.16$ \\
\hline
\end{tabular}

Data represent the mean \pm SEM animal swim distance $(\mathrm{cm})$ and speed $(\mathrm{m} / \mathrm{s})$ during each recall test. Significant difference from saline control is indicated by an asterisk (Mann-Whitney U-test; $p<0.05$ ).

cognition-enhancing potential of selective $5-\mathrm{HT}_{6}$ receptor antagonists have been demonstrated in mature rats (Rogers and Hagan, 2001; Woolley et al, 2001). The precise mechanism(s) by which $5 \mathrm{HT}_{6}$ receptor antagonists mediate their cognition-enhancing action still remain to be elucidated. The results obtained in the present study suggest that these actions may, in part, relate to facilitation of the cholinergic system, a conclusion supported by the recent report that the $5-\mathrm{HT}_{6}$ receptor antagonist Ro 04-6790 produced a modest, nonsignificant increase in extracellular acetylcholine levels as measured by in vivo microdialysis (Shirazi-Southall et al, 2002). However, it must be noted that $5-\mathrm{HT}_{6}$ receptor antagonists also augment glutamate release in the frontal cortex and hippocampus (Dawson et al, $2000,2001)$, a transmitter system integral to neuroplastic events associated with memory formation (Bliss and Collingridge, 1993). It is noteworthy that in these in vivo microdialysis studies, atropine, at doses previously reported to antagonize the cholinergic-like effects in $5-\mathrm{HT}_{6}$ receptor antisense oligonucleotide studies (Bourson et al, 1995), had no effect on the SB-271046-induced increases in extracellular glutamate (Dawson et al, 2001), suggesting that the enhanced excitatory amino-acid neurotransmission was not a direct consequence of an enhanced cholinergic function. Immunohistochemical data on the localization of $5-\mathrm{HT}_{6}$ receptors suggest that they may be located on GABAergic spiny neurons in the striatum (Gérard et al, 1997) and in GABAergic/peptidegic striatopalladial and striatal nigro output pathways (Ward and Dorsa, 1996). More recent data have demonstrated colocalization of glutamic acid decarboxylase (GAD) and $5-\mathrm{HT}_{6}$ receptors in the rat cerebral cortex and hippocampus (Fone, 2000). Collectively, these data suggest that $5-\mathrm{HT}_{6}$ receptor antagonists may modulate cholinergic and/or glutamatergic systems indirectly via disinhibition of GABAergic neurons.

In summary, we demonstrate that acute administration of SB-271046 reverses a scopolamine deficit in a passive avoidance task and chronically it has been shown to improve task acquisition and recall in a spatial learning paradigm in aged rats. Taken together, these results further support the rationale for the use of $5-\mathrm{HT}_{6}$ receptor antagonists in the treatment of cognitive dysfunction associated with disorders such as schizophrenia and Alzheimer's disease.

\section{ACKNOWLEDGEMENTS}

This work was supported by a research grant from GlaxoSmithKline.

\section{REFERENCES}

Bartus RT, Dean RL, Beer B, Lippa AS (1982). The cholinergic hypothesis of geriatric memory dysfunction. Science 217: 408-417.

Bentley JC, Bourson A, Boess FG, Fone KFC, Marsden CS, Petit N et al (1999). Investigation of stretching behaviour induced by the selective $5-\mathrm{HT}_{6}$ receptor antagonist, Ro-04-6790, in rats. $\mathrm{Br} \mathrm{J}$ Pharmacol 126: 1537-1542.

Bliss TVP, Collingridge GL (1993). A synaptic model of memory: long-term potentiation in the hippocampus. Nature 361: 31-39.

Bromidge SM, Brown AM, Clarke SE, Dodgson K, Gager T, Grassam HL et al (1999). 5-Chloro-N-(4-methoxy-3-piperazin-1yl- phenyl)-3-methyl-2-benzothiophenesulfon- amide (SB271046): a potent, selective, and orally bioavailable 5-HT6 receptor antagonist. J Med Chem 42: 202-205.

Bromidge SM, Clarke SE, Gager T, Griffith K, Jeffrey P, Jennings AJ et al (2001). Phenyl benzenesulfonamides are novel and selective $5-\mathrm{HT}_{6}$ antagonists: Identification of $\mathrm{N}$-(2,5-dibromo-3-fluorophenyl)-4-methoxy-3-piperazin-1-ylbenzenesulfonamide (SB357134). Bioorg Med Chem Lett 11: 55-58.

Bös M, Sleight A, Godel T, Martin JR, Riemer C, Stadler H (2001). $5-\mathrm{HT}_{6}$ receptor antagonists: lead opptimisation and biological evaluation of $\mathrm{N}$-aryl and $\mathrm{N}$-heteroaryl 4 -amino-benzene sulfonamides. Eur J Med Chem 36: 165-178.

Bourson A, Boess FG, Bös M, Sleight AJ (1998). Involvement of 5$\mathrm{HT}_{6}$ receptors in nigro-striatal function in rodents. $\mathrm{Br} J$ Pharmacol 125: 1562-1566.

Bourson A, Borroni E, Austin RH, Monsma Jr F, Sleight AJ (1995). Determination of the role of the $5-\mathrm{ht}_{6}$ receptor in the rat brain: a study using antisense oligonucleotides. J Pharmacol Exp Ther 274: $173-180$.

Coyle JT, Price DL, DeLong MR (1983). Alzheimer's disease: a disorder of cortical cholinergic innervation. Science 219: 1184-1190.

Dawson L, Nguyen HQ, Li P (2000). In vivo effects of the $5 \mathrm{HT}_{6}$ receptor antagonist SB-270146 on striatal and frontal cortex extracellular concentrations of noradrenaline, dopamine, 5-HT, glutamate and aspartate. Br J Pharmacol 130: 23-26.

Dawson L, Nguyen HQ, Li P (2001). The $5 \mathrm{HT}_{6}$ receptor antagonist SB-271046 selectively enhances excitatory neurotransmission in the rat frontal cortex and hippocampus. Neuropsychopharmacology 25: 662-668. 
Doyle E, Regan CM (1993). Cholinergic and dopaminergic agents which inhibit a passive avoidance response attenuate the paradigm-specific increases in NCAM sialylation state. J Neural Transm 92: 33-49.

Fone CF (2000). The 5-ht6 receptor: Potential CNS functions. $\mathrm{Br} J$ Pharmacol 131: 238P.

Fox GB, O'Connell AW, Murphy KJ, Regan CM (1995). Memory consolidation induces a transient and time-dependent increase in the frequency of NCAM-polysialylated cells in the adult rat hippocampus. J Neurochem 65: 2796-2799.

Gage FH, Dunnett SB, Bjorklund A (1984). Spatial learning and motor deficits in aged rats. Neurobiol Aging 5: 43-48.

Gallagher M, Pelleymounter MA (1988). Spatial learning deficits in old rats: a model for memory decline in the aged. Neurobiol Aging 9: 549-556.

Gérard C, Martres M-P, Lefévre K, Miquel M-C, Vergé D, Lanfumey $\mathrm{L}$ et al (1997). Immuno-localization of serotonin $5 \mathrm{HT}_{6}$ receptor-like material in the rat central nervous system. Brain Res 746: 207-219.

Hamon M, Doucet E, Lefévre K, Miquel M-C, Lanfumey L, Insausti $\mathrm{R}$ et al (1999). Antibodies and antisense oligonucleotide for probing the distribution and putative functions of central $5-\mathrm{HT}_{6}$ receptors. Neuropsychopharmacology 21: 68S-76S.

Hirst WD, Minton JAL, Bromidge SM, Moss SF, Latter AJ, Riley G et al (2000). Characterization of $\left[{ }^{125} \mathrm{I}\right]-\mathrm{SB}-258585$ binding to human recombinant and native $5-\mathrm{HT}_{6}$ receptors in rat, pig and human brain tissue. Br J Pharmacol 130: 1597-1605.

Meneses A (1999). 5-HT system and cognition. Neurosci Biobehav Rev 23: $1111-1125$.

Meneses A (2001). Effects of the 5- $\mathrm{HT}_{6}$ receptor antagonist Ro 046790 on learning consolidation. Behav Brain Res 118: 107-110.

Monsma FJ, Shen Y, Ward RP, Hamblin MW, Sibley DR (1993). Cloning and expression of a novel serotonin receptor with high affinity for tricyclic psychotrophic drugs. Mol Pharmacol 43: 320-327.

Murphy KJ, O’Connell AW, Regan CM (1996). Repetitive and transient increases in hippocampal neural cell adhesion molecule polysialylation state following multi-trial spatial training. J Neurochem 67: 1268-1274.

Perry K, Johnson M, Kerwin JM, Piggott MA, Court JA, Shaw PJ et al (1992). Convergent cholinergic activities in aging and Alzheimer's disease. Neurobiol Aging 13: 393-400.
Rapp PR, Rosenberg RA, Gallagher M (1987). An evaluation of spatial information processing in aged rats. Behav Neurosci 101: 3-12.

Reavill C, Rogers DC (2001). The therapeutic potential of $5 \mathrm{HT}_{6}$ receptor antagonists. Curr Opin Invest Drugs 2: 104-109.

Routledge C, Bromidge SM, Moss SF, Price GW, Hirst WD, Newman $\mathrm{H}$ et al (2000). Characterization of SB-271046: A potent, selective and orally active $5-\mathrm{HT}_{6}$ receptor antagonist. $\mathrm{Br} \mathrm{J}$ Pharmacol 130: 1606-1612.

Rogers DC, Hagan JJ (2001). 5- $\mathrm{HT}_{6}$ receptor antagonists enhance retention of a water maze task in the rat. Psychopharmacology 158: $114-119$.

Ruat M, Traiffort E, Arrrang J-M, Tardivel-Lacombe J, Diaz J, Leurs $\mathrm{R}$ et al (1993). A novel serotonin $\left(5-\mathrm{HT}_{6}\right)$ receptor: molecular cloning, localisation and stimulation of cAMP accumulation. Biochem Biophys Res Commun 193: 268-276.

Shirazi-Southall S, Rodriguez DE, Nomikos GG (2002). Effects of typical and atypical antipsychotics and receptor selective compounds on acetylcholine efflux in the hippocampus of the rat. Neuropsychopharmacology 26: 583-594.

Sleight A, Boess FG, Bös M, Levet-Trafit B, Riemer C, Bourson A (1998). Characterization of Ro 04-6790 and Ro 63-0563: potent and selective antagonists at human and rat 5- $\mathrm{HT}_{6}$ receptors. $\mathrm{Br} \mathrm{J}$ Pharmacol 124: 556-562.

Stean TO, Hirst WD, Thomas DR, Price GW, Rogers DC, Riley G et al (2002). Pharmacological profile of SB-357134: A potent, selective, brain penetrant and orally active $5-\mathrm{HT}_{6}$ receptor antagonist. Pharmacol Biochem Behav 71: 645-654.

van der Staay FJ, de Jonge M (1993). Effects of age on water escape behavior and on repeated acquisition in rats. Behav Neural Biol 60: 33-41.

Ward RP, Dorsa DM (1996). Colocalization of serotonin receptor subtypes $5-\mathrm{HT}_{2 \mathrm{~A}}, 5-\mathrm{HT}_{2 \mathrm{C}}$ and $5-\mathrm{HT}_{6}$ with neuropeptides in rat striatum. J Comp Neurol 370: 405-414.

Whitehouse PJ, Price DL, Struble RG, Clark A, Coyle JT, De Long MR (1982). Alzheimer's disease, and senile dementia: loss of neurons in the basal forebrain. Science 215: 1237-1240.

Woolley ML, Bentley JC, Sleight AJ, Marsden CA, Fone KCF (2001). A role for $5-\mathrm{HT}_{6}$ receptors in retention of spatial learning in the Morris water maze. Neuropharmacology 41: 210-219. 